\title{
NORMATIZAÇÃO CONTÁBIL BASEADA EM PRINCÍPIOS OU EM REGRAS? BENEFÍCIOS, CUSTOS, OPORTUNIDADES E RISCOS
}

\section{PRINCIPLES-BASED OR RULES-BASED ACCOUNTING STANDARDS? BENEFITS, COSTS, OPPORTUNITIES AND RISKS}

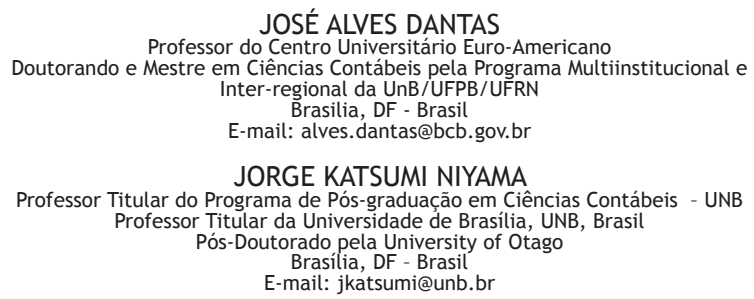

FERNANDA FERNANDES RODRIGUES

Doutoranda e Mestre em Ciências Contábeis pela Proorama Multiinstitucional e Inter-regional da UnB/UFPB/UFRN

Brasilia, DF- Brasil
E-mail: fernandes@unb.br

PAULO CESAR DE MELO MENDES Professor da Universidade de Brasília, UNB, Brasil. Doutorando e Mestre em Ciências Contábeis pela Programa Multiinstitucional e Inter-regional da UnB/UFPB/UFRN E-mail: mendes@unb.b

\section{RESUMO}

O processo de convergência dos padrões contábeis e a constatação de que os casos de engenharia financeira que deram origem aos escândalos corporativos do início do século, nos EUA, foram facilitados pelo modelo dos US-GAAP, baseado em regras, produziram um grande debate sobre a conveniência de se adotar, naquele país, um sistema baseado em princípios. No Brasil, tem avançado o movimento de convergência às normas do IASB, tidas como baseadas em princípios, mas ainda há carência de estudos acadêmicos que discutam mais profundamente as vantagens e desvantagens de uma normatização contábil baseada em regras ou em princípios. 0 objetivo do presente estudo é promover uma revisão a respeito dos benefícios, custos, oportunidades e riscos decorrentes da adoção de sistemas contábeis cujas normas sejam baseadas em princípios ou em regras. Os resultados demonstram que cada modelo possui pontos positivos e negativos, que devem ser adequadamente avaliados antes de uma decisão por parte dos órgãos reguladores, dos profissionais e dos usuários. É constatado, também, que o modelo baseado em princípios tem prevalecido nessas discussões, embora alguns estudos cheguem a apontar a necessidade de uma referência intermediária, definida como "baseada em objetivos".

Palavras-chave: Fasb; US-GAAP e convergência dos padrões contábeis

\section{ABSTRACT}

The convergence process of accounting standards and the evidence that the financial fraud cases in the beginning of the century in the USA were encouraged by the "rulesbased" orientation (US-GAAP model) produced a great debate over the appropriateness to adopt, alternatively, the principles-based accounting standards. Brazilian law and the statements published by the Accounting Pronouncements Committee (CPC) required the progressive convergence of Brazilian GAAP with IFRS which are considered to be principlesbased accounting. However, we have no enough evidence of academic studies over the advantages and disadvantages of accounting standards based on rules or principles. The main purpose of this paper is to provide an insight on the benefits, costs, opportunities and risks arising from the adoption of accounting standards based on either principles or rules. According to the research, each model has strengths and weaknesses, which must be adequately evaluated before a decision by regulatory bodies, accountants, professionals and users. As far as this research has pursued, a principles-model has been prevail in this debate, although some studies also identify the need of an intermediate reference, defined as "based on goals".

Key-words: FASB, US-GAAP and convergence of accounting standars. 


\section{INTRODUÇÃO}

O avanço do processo de convergência dos padrões contábeis, com a adoção das International Financial Reporting Standards (IFRS), editadas pelo International Accounting Standards Board (IASB), ganhou relevância especial no início dos anos 2000, com a exigência de sua adoção no âmbito dos países da comunidade econômica européia. No Brasil, os esforços para esse movimento de harmonização começaram, segundo a Comissão de Valores Mobiliários (CVM), ${ }^{1}$ na década de 1990, e apresentam alguns fatos marcantes, entre os quais se pode destacar: a edição da Circular $n^{\circ} 3.068$, de 8.11.2001, por parte do Banco Central do Brasil (BCB), determinando critérios para classificação e avaliação de títulos e valores mobiliários de acordo com preceitos das normas internacionais; a criação, em 2005, do Comitê de Pronunciamentos Contábeis (CPC), com o objetivo de estudar, preparar e emitir pronunciamentos técnicos com vistas ao processo de convergência aos padrões internacionais; a edição da Instrução CVM n 457/2007, determinando que a partir do exercício findo em 2010, as companhias abertas devem apresentar demonstrações financeiras consolidadas adotando o padrão contábil internacional - normas do IASB; a promulgação da Lei $n^{\circ}$ 11.638, de 28.12.2007, alterando dispositivos relativos ao processo de elaboração e de divulgação das demonstrações financeiras.

Embora o seu objetivo central seja o desenvolvimento de normas de alta qualidade, que sejam exigidas e aceitas globalmente, aperfeiçoando a divulgação financeira e o funcionamento dos mercados, o processo de convergência dos padrões contábeis traz em seu contexto uma reflexão mais profunda do que simplesmente a mudança de normas orientadoras sobre o reconhecimento, a classificação, a mensuração e o disclosure de eventos econômicos.

Contempla, também, uma discussão sobre qual deve ser a linha central para a estruturação normativa do sistema contábil: definir regras detalhadas para os diversos eventos econômicos, priorizando o objetivo de produzir informações consistentes e comparáveis e menos suscetíveis à subjetividade de quem as elabora; ou estabelecer princípios gerais que devem nortear o contador e o auditor em seu julgamento profissional sobre a melhor forma de reconhecer, classificar, mensurar e divulgar cada evento, tendo por propósito informações contábeis que reflitam o mais apropriadamente possível a essência econômica da operação.

Não obstante o fato de o movimento de aceitação e de adesão às normas do IASB, tidas como baseadas em princípios, revelar, de certa forma, que esse tipo de modelo tem prevalecido sobre o baseado em regras, não há unanimidade entre os estudiosos, pesquisadores e profissionais da Contabilidade quanto à conveniência de se adotar uma estrutura normativa que se caracteriza pela ausência de critérios mais específicos para o tratamento dos diversos eventos.

Essa discussão sobre as vantagens e as desvantagens de cada um desses modelos tem sido particularmente relevante nos Estados Unidos (EUA), onde o modelo dos Generally Accepted Accounting Principles (US-GAAP), editados pelo Financial Accounting Standards Board (FASB), é geralmente citado como um exemplo 1 Conforme os “considerandos” da Instrução Normativa n 457, de 13.7.2007. 
de sistema de normas baseadas em regras $^{2}$ (ALEXANDER; JERMAKOWICZ, 2006), ao mesmo tempo em que há pressões para sua modificação, conforme discutido mais apropriadamente na seção 3.

No Brasil, apesar do avanço na implementação das IFRS, por meio dos pronunciamentos do CPC, as discussões têm se concentrado sobre os benefícios associados ao processo de convergência: redução de custo de elaboração de relatórios contábeis; redução de riscos e custos nas análises e decisões; e redução de custo de capital. Não há evidências, porém, de estudos acadêmicos que avaliem as vantagens e as desvantagens desse processo a partir de uma reflexão sobre as características de modelos de normatização baseados em princípios ou em regras.

Nesse contexto, o objetivo do presente estudo é promover uma revisão a respeito dos benefícios, custos, oportunidades e riscos - em síntese, vantagens e desvantagens - decorrentes da adoção de sistemas contábeis cujas normas sejam baseadas em princípios ou em regras. O propósito é identificar elementos que possam servir de referência para uma maior reflexão sobre o tema no âmbito interno, tendo em vista o avanço, no Brasil, do processo de convergência às normas emitidas pelo IASB. Não pretende o estudo esgotar o tema e nem oferecer soluções objetivas para essa questão, mas levantar argumentos positivos e negativos a respeito de cada sistema, de forma a contribuir para o aprofundamento das discussões e a qualidade do arcabouço normativo contábil brasileiro.

Para o alcance desse objetivo, a pesquisa se sustenta, essencialmente, em um processo de revisão de literatura, procurando se basear nas reflexões teóricas de pesquisadores e de autoridades de regulação para identificar aspectos que possam ser destacados como benefícios, custos, oportunidades e riscos do processo de convergência do modelo contábil brasileiro para um padrão reconhecidamente mais baseado em princípios do que em regras.

Além desta seção introdutória, o artigo: discute o processo de normatização contábil, com destaque para o conceito de visão verdadeira e justa da informação financeira e a especificação de um sistema contábil baseado em princípios ou em regras (seção 2); relata o debate sobre a qualidade das normas contábeis norteamericanas, especificando os estudos em andamento para a eventual mudança do modelo em vigor (seção 3); ressalta a importância das características qualitativas da informação contábil, como parâmetro de análise para a decisão sobre a conveniência de se adotar um modelo baseado em princípios ou em regras (seção 4); trata dos efeitos e consequências da adoção de cada modelo (seção 5); discute a situação brasileira, destacando o processo de convergência às normas do IASB e em que contexto se insere o debate entre princípios e regras (seção 6); e, por fim, apresenta uma síntese das discussões sobre o tema (seção 7).

2 Cabe ressaltar, de acordo com Schipper (2003), que apesar de os US-GAAP serem, de forma geral, citados como normas baseadas em regras, eles são originalmente suportados na estrutura conceitual, o que atenderia aos preceitos de baseados em princípios. 0 que os torna baseados em regras são as exceções de escopo e de tratamento, conforme discutido na seção 2 . 


\section{O PROCESSO DE NORMATIZAÇÃO CONTÁBIL}

Embora desde os trabalhos de Ball e Brown (1968) e de Beaver (1968), as pesquisas quantitativas, de natureza positiva, notadamente as que relacionam informações financeiras e o mercado de capitais, tenham se tornado a principal linha dos estudos empreendidos no âmbito da Contabilidade, conforme destaca Kothari (2001), as pesquisas com abordagem normativa continuam a exercer papel relevante para a evolução do conhecimento contábil.

A esse respeito, inclusive, Lopes, ludícibus e Martins (2008) afirmam que o normativismo, apesar das críticas dos positivistas, não foi inútil e não criou instrumentos sem valor. Ao contrário, o que existe de teoria e de prática profissional veio quase em totalidade desse movimento. Segundo Previts e Merino (1998, apud LOPES, 2002), a inserção acadêmica da Contabilidade se deu sob a influência da profissão, com o objetivo de apresentar respostas às suas demandas, ao contrário do que ocorre em outras áreas de conhecimento. Como consequência, os primeiros pesquisadores tinham um caráter extremamente normativo, voltado a recomendar as melhores práticas e procedimentos aos profissionais.

Essa preocupação com o ordenamento normativo é coerente com a afirmação de Hendriksen e Van Breda (1999) de que um dos preceitos da importância da Contabilidade é o seu pragmatismo, ou seja, a sua utilidade para os usuários. Como exemplo, destacam o fato de que a regulamentação, nos EUA, começou com a criação do primeiro organismo regulador, o Interstate Commerce Commission (ICC), que procurou estabelecer um sistema contábil uniforme, em resposta a manipulações para aumentar o preço das ações das estradas de ferro. Na Grã-Bretanha, apesar de se enfrentar o mesmo tipo de problema, passou-se a exigir, por meio de leis, volumes crescentes de divulgação financeira específica e geral nos relatórios anuais das empresas. Em síntese, ainda segundo Hendriksen e Van Breda (1999), a regulamentação contábil surgiu em decorrência de questões objetivas, embora tenham adotado modelos distintos - política de regulação por uniformidade, nos EUA, e política de regulação por divulgação, na Grã-Bretanha.

Nos anos 1930, os prejuízos causados pela quebra da Bolsa de Valores de Nova York provocaram maior preocupação quanto à qualidade das informações contábeis. Surgiu, então, a necessidade de se criar um organismo que fosse capaz de garantir que a Contabilidade atendesse aos interesses dos usuários, conforme ludícibus e Lopes (2004). Em 1934, foi criada a Securities and Exchange Commission (SEC), e os princípios e normas contábeis que foram adotados refletiam o desejo de garantir a segurança e a objetividade da informação.

Nesse contexto, avança o processo de regulação contábil, definido por ludícibus e Lopes (2004) como sendo um conjunto de normas coercitivas relativas a determinada matéria ou área do conhecimento, advindas do Estado ou de órgão com poderes para isso. No Brasil, em particular, a regulamentação contábil se inicia, de acordo com Niyama e Silva (2008), com o primeiro Código Comercial Brasileiro, de 1850, que obrigou as empresas a manterem escrituração contábil, e com a Lei 1.083 , de 1860, considerada a primeira lei das sociedades anônimas, e que exigiu a 
publicação das demonstrações.

Apesar do razoável consenso quanto à necessidade de se estabelecer um padrão normativo que sirva de referência para a atuação dos profissionais, em razão de os mecanismos de mercados eventualmente serem falhos ou contrários aos interesses da sociedade, não há unanimidade quanto ao modelo a ser utilizado. Nesse particular, destacam-se discussões sobre a adoção ou não do conceito true and fair view, bem como sobre a implementação de modelos normativos baseados em princípios ou em regras.

\section{1 - TRUE AND FAIR VIEW (TFV)}

O conceito true and fair view foi originado no Reino Unido e preceitua que nas demonstrações financeiras deve prevalecer uma visão verdadeira e justa da situação econômico-financeira do negócio e dos resultados, inclusive sobre os eventuais dispositivos legais e normativos. Isso significa dizer que, mesmo em situações em que a norma contábil estabeleça determinados registros e divulgações, se o profissional entender que, seguindo a norma, a essência econômica será afetada, ele deve priorizar o conceito de TFV e não as previsões normativas.

Segundo Alexander e Jermakowicz (2006), a visão verdadeira e justa tem sido exportada para muitos países e, com a ascensão do Reino Unido à União Européia, tornou-se parte da lei européia, além de estar presente na International Accounting Standard (IAS) 1, que trata da apresentação das demonstrações financeiras. Não obstante, o conceito TFV permanece sem uma clara definição nos instrumentos legais, o que o torna sujeito a diferentes interpretações.

Em síntese, o objetivo do conceito TFV é deixar as companhias com alguma liberdade para escolher o critério contábil, contanto que as escolhas sejam aceitas pelos auditores independentes e claramente evidenciadas, podendo oferecer aos usuários a percepção dos administradores a respeito dos negócios, o que pode se revelar útil para a compreensão da situação econômico-financeira e dos resultados da empresa. Segundo Jreige (1998), pelo fato de o conceito TFV não ser expressamente definido, as discussões acerca da supremacia da visão verdadeira e justa sobre os requisitos legais e os princípios contábeis têm se focado, especialmente, na sua subjetividade. A alegação dos seus opositores é que tal expressão serviria apenas de pretexto para que a administração pudesse fazer o que mais the conviesse.

Nos EUA, por exemplo, a liberdade implícita no conceito TFV sempre foi repelida, assumindo-se como requisito essencial para a elaboração e a divulgação das demonstrações financeiras, os princípios contábeis geralmente aceitos, denominados US-GAAP. Tem-se, assim, uma diferença essencial em relação aos dois modelos: em um, a qualidade da demonstração financeira, a ser atestada pelo auditor, é se ela evidencia uma visão verdadeira e justa sobre as operações, o patrimônio e os resultados da organização; e em outro, a referência do auditor para avaliar a qualidade dos relatórios financeiros é a observância aos princípios contábeis geralmente aceitos. 
A respeito da subjetividade inerente à TFV, Parker e Nobes (1991) destacam que é um conceito filosófico, não suscetível de ser definido por regras detalhadas. É essencialmente uma questão de ética e moralidade, o que implica assumir que contadores, usuários e auditores das demonstrações financeiras partilham uma compreensão comum dos propósitos da informação financeira. O pressuposto é que, por conhecer mais apropriadamente o negócio, a administração pode preparar melhores informações que aquelas imaginadas pelo regulador, conforme destaca Jreige (1998). Adicionalmente, a mesma autora ressalta que para se contrapor às críticas de que o TFV, pela sua subjetividade, facilitaria o gerenciamento de resultados, os seus defensores destacam que os abusos seriam evitados pela auto-regulação do mercado.

Em síntese, os argumentos a favor do conceito TFV - um dos pilares da contabilidade baseada em princípios, segundo Alexander e Jermakowicz (2006) - têm se concentrado basicamente no pressuposto de que busca a expressão verdadeira e justa nas demonstrações financeiras, com a prevalência da essência sobre a forma. Por outro lado, suscita diversos questionamentos sobre a pertinência de sua adoção, basicamente em função de eventuais consequências indesejadas decorrentes do uso da subjetividade por parte da administração.

\section{2 - SISTEMA CONTÁBIL BASEADO EM PRINCÍPIOS}

De acordo com Schipper (2003), a referência principal para se considerar as normas contábeis como baseada em princípios é o fato de serem guiadas pela estrutura conceitual, garantindo que a divulgação financeira seja relevante para os investidores, e que os requisitos de reconhecimento e de mensuração sejam baseados nas características qualitativas da informação contábil. Benston, Bromwich e Wagenhofer (2006), por sua vez, ao refletirem sobre os padrões contábeis dos Estados Unidos, ressaltam que, apesar da ênfase dada de que estão em conformidade com os princípios contábeis geralmente aceitos, são mais baseados em regras que em princípios, pelo número de tratamentos específicos que contemplam.

A partir dessas reflexões de Schipper (2003) e Benston, Bromwich e Wagenhofer (2006), é possível se definir um sistema contábil como sendo "baseado em princípios" quando as normas que dão sustentação à atuação profissional têm por base uma estrutura conceitual e não estabelecem critérios específicos para o tratamento de situações particulares. Pode ser expresso, segundo Alexander e Jermakowicz (2006), como um conjunto de noções, convenções ou forma de pensar que são consistentemente aplicadas para situações familiares e não-familiares. A distinção em relação ao TFV é que, apesar da visão verdadeira e justa ser considerada uma fortaleza do sistema baseado em princípios, esse requer o estabelecimento de referências a serem consideradas no julgamento profissional, enquanto o TFV se sustenta em um conceito fundamental, de natureza abrangente, não traduzido em uma definição clara e objetiva.

O pressuposto é que as normas baseadas em princípios não determinam como 
fazer, mas sim como decidir o que necessita ser feito. Ao invés de especificar claramente como promover a classificação, o reconhecimento, a mensuração e a divulgação de cada evento econômico, oferecem diretrizes para o julgamento profissional de cada situação particular. Em resumo, sugerem a preparação dos contadores e dos auditores para que estes decidam o que é necessário fazer e como se deve fazer. A justificativa é que o oferecimento de um referencial para o julgamento profissional, combinado com a possibilidade de o contador e o auditor decidirem a melhor forma de elaborar e divulgar as informações a respeito das operações da empresa, permite a consideração da essência do negócio, tendo em vista que nem todas as nuances de uma operação poderiam ser apropriadamente antecipadas pelos reguladores.

As críticas a esse modelo concentram-se, essencialmente, na subjetividade do julgamento profissional, o que pode facilitar ou induzir o gerenciamento de resultados, bem como na perda de comparabilidade, tendo em vista que cada profissional pode julgar questões semelhantes de forma diferente. Como atenuante, há que se ressaltar o fato de que a ampla evidenciação das bases utilizadas para os julgamentos profissionais cria condições para que os usuários das demonstrações contábeis identifiquem essas eventuais diferenças no processo de divulgação financeira.

Os defensores do modelo argumentam, porém, segundoAlexander e Jermakowicz (2006), que o conteúdo das demonstrações financeiras é inerentemente subjetivo, sendo mais construções intersubjetivas que realidades mentalmente independentes, por duas razões: primeiro, porque a informação pode ser percebida, apresentada e interpretada por diferentes pessoas e de diferentes formas; e segundo, porque considerando a flexibilidade e a inventividade da mente humana, regulamentos detalhados podem nunca ser suficientemente completos nem apropriadamente relevantes para dizer adequadamente o que os contadores devem fazer. Com isso, uma harmonização absoluta seria impossível tanto filosoficamente quanto em sua natureza.

Por analogia, podem ser aplicados a essa situação os preceitos da teoria dos contratos incompletos, definidos como instrumentos cujo desempenho de seus termos deixam ganhos potenciais de transação irrealizados, face às informações disponíveis para os agentes no momento em que ocorre (GALLO, 2009). Por essa teoria, quaisquer que sejam as transações, as partes envolvidas não sabem ao certo se os termos acordados irão se efetivar, pois a execução e cumprimento do que foi acordado está na dependência de fatores externos, normalmente imprevisíveis no momento da contratação.

Os padrões editados pelo IASB têm sido apontados como exemplo de normas baseadas em princípios, por serem concebidas, conforme Lopes, Galdi e Lima (2009), dentro de uma tradição jurídica consuetudinária (common law), oferecendo princípios gerais de orientação e não regras detalhadas, de forma a possibilitar que a essência econômica das operações seja evidenciada. Niyama e Silva (2008) também ressaltam essa característica, destacando que o IASB segue uma política flexível na elaboração e na publicação de normas, indicando, em alguns casos, a adoção de mais de um procedimento contábil válido para uma mesma modalidade operacional. 
Lopes, Galdi e Lima (2009) destacam que nesses padrões há considerável espaço para o julgamento profissional, exemplificando com o caso dos instrumentos financeiros, nos quais as normas indicam a necessidade de apreciar e decidir sobre as seguintes questões: a essência econômica da operação, necessária para a decisão do momento do reconhecimento ou desreconhecimento da operação; a classificação do instrumento financeiro de acordo com a intenção da operação; a avaliação do valor justo do instrumento financeiro; e a identificação da finalidade da operação - hedge ou trading.

Essa afirmação de que as normas editadas pelo IASB são baseadas em princípios se sustenta principalmente pela comparação em relação aos US-GAAP ou aos BRGAAP pré-CPC, pelo fato desses efetivamente possuírem bem menos espaço para o julgamento profissional que os padrões das IFRS. Na prática, porém, nem todas as normas que constituem o modelo do IASB são totalmente pautadas em princípios. Algumas delas contêm regras de implementação bem específicas, como é o caso da IFRS $8^{3}$, que trata da divulgação de informações por segmentos, onde são previstos requisitos detalhados em relação ao volume de receitas, de ativos e/ou de resultados para se concluir sobre quais segmentos devem ser evidenciados. A existência de normas muito extensas ${ }^{4}$, bem como o conteúdo dos Basis for Conclusions, onde o Board justifica as razões para se optar por uma determinada forma de pronunciamento, também oferecem evidências para se questionar a afirmação de que o modelo do IASB é completamente baseado em princípios.

\section{3 - SISTEMA CONTÁBIL BASEADO EM REGRAS}

Um sistema contábil é tido como "baseado em regras", a partir dos preceitos de Schipper (2003) e Benston, Bromwich e Wagenhofer (2006), quando proveem normas detalhadas com métodos específicos para o tratamento de todos os problemas e situações esperados. Não significa, necessariamente, que sua previsão seja feita sem considerar uma estrutura conceitual como referência. A característica central é buscar estabelecer critérios que procurem alcançar questões específicas.

É o caso, em particular, conforme Alexander e Jermakowicz (2006), das normas contábeis norte-americanas, que, apesar de denominadas "princípios contábeis geralmente aceitos", compreendem convenções, regras e procedimentos necessários para definir as práticas contábeis aceitas em determinada situação. A palavra "princípio" não tem, portanto, um sentido estrito. Embora baseadas em uma estrutura conceitual, as normas emitidas pelo FASB são suplementadas por orientações ou guias de implementação e de interpretação muito detalhadas, determinando como deve ser feito. São casos em que a aplicação da norma geral não é suficientemente clara e adequada. De acordo com o FASB (2002), o número de exceções a um padrão básico e a quantidade de julgamentos necessários para aplicar

3 Incorporado no modelo brasileiro pelo CPC 22.

4 Como é o caso da IAS 39, que detalha procedimentos para o reconhecimento e a mensuração de ativos financeiros em 268 páginas, ou da IFRS 3, que trata de combinações de negócios em 172 páginas (IASB, 2009). 
uma norma são os direcionadores de complexidade dos padrões contábeis, razão que justificaria a necessidade de regras e orientações.

Segundo Schipper (2003), embora as normas do FASB sejam originalmente emitidas com base na estrutura conceitual, o que atenderia ao preceito de "baseado em princípios", são seguidas de guias detalhadas que admitem exceções de escopo e de tratamentos. Ou seja, as orientações não são apenas detalhamentos das normas originais, permitindo, inclusive: a sua não aplicação em determinados casos (exceções de escopo), geralmente para evitar conflitos com corporações ou outros órgãos emissores de normas específicas; ou a aplicação a situações particulares (exceções de tratamento), muitas vezes para limitar a volatilidade dos resultados divulgados ou para permitir o atendimento a demandas específicas de segmentos.

Como exemplos de exceção de escopo, a autora cita: os contratos de seguros, que geralmente são excluídos de normas aplicáveis a determinados tipos de empresas; os acordos de benefícios a empregados, que são excluídos do alcance das normas relativas a instrumentos financeiros; as exceções listadas na Statement of Financial Accounting Standard (SFAS) 133 para a definição de um derivativo, sendo que várias delas são claramente com a intenção de reduzir custos para os preparadores das demonstrações. Para as exceções de tratamento, são listados como exemplos: a SFAS 115, que prevê três categorias de títulos de mercado, cada uma com tratamento contábil específico; a SFAS 143, que permite desvios em relação à mensuração do fair value, explicitamente para reduzir a volatilidade do resultado; a SFAS 140, que permite a utilização de sociedades de propósitos específicos para o tratamento de desreconhecimento em certos contratos envolvendo ativos financeiros.

O resultado dessas exceções é o aumento do nível de detalhes e da complexidade das normas, o que pode tornar mais oneroso e difícil o processo de elaboração e divulgação financeira, impactando sua efetividade.

Para os seus defensores, segundo Alexander e Jermakowicz (2006), o sistema baseado em regras é definido como o estabelecimento de "linhas claras", tendo em vista que eliminaria as eventuais dúvidas de interpretação de uma norma de caráter geral e seria um importante instrumento de uniformidade de atuação, o que garantiria a comparabilidade das informações produzidas. Os seus opositores, por sua vez, denominam-no pejorativamente de "cookbook approach", "indigestão contábil" ou "sobrecarga de padrões". Os ingleses, em particular, ainda de acordo com esses autores, refutam a premissa de "linhas claras", destacando ser mais apropriado tratá-lo como “obscurantismo”, por induzir a interpretação literal.

Entre os críticos desse modelo, destaca-se o argumento de que as regras são, por natureza, incompletas e podem tornar as normas inflexíveis ao longo do tempo, dificultando as adaptações a novas situações conjunturais e ambientais, tornando-se obsoletas. Além do mais, ao não permitir a incorporação da percepção da administração, pode limitar a qualidade da informação divulgada aos usuários. Por fim, o aumento dos detalhes, notadamente com exceções especiais, torna as normas especialmente complexas, dificultando sua aplicabilidade. 


\section{3 - DEBATE SOBRE A QUALIDADE DOS US-GAAP}

Embora os US-GAAP sejam baseados em uma estrutura conceitual, são suplementados por orientações detalhadas de implementação e de interpretação, que proporcionam, segundo Alexander e Jermakowicz (2006), soluções contábeis mais coerentes com a letra da lei/norma que com o seu espírito. A esse respeito, inclusive, Hendriksen e Van Breda (1999) afirmam que a estrutura conceitual não tem sido o motor do estabelecimento de padrões que seus proponentes imaginavam, tendo em vista que, na prática, são extraídos termos da estrutura conceitual para reforçar argumentos, mas o que prevalece são, essencialmente, as decisões políticas, como previam os críticos.

Esse modelo se consolidou principalmente a partir da crise de 1929, quando a Contabilidade foi questionada pela ausência de padrão das informações divulgadas, o que teria dificultado a percepção dos investidores quanto à situação financeira das companhias. A partir dos escândalos corporativos do início dos anos 2000 - como os da Enron, da WorldCom e da Tyco - o modelo contábil americano, porém, passou a ser criticado quanto à sua eficácia, sendo-lhe atribuída parte da culpa pelas ações de engenharia financeira promovidas pelas empresas, que estão na origem dos graves problemas identificados na ocasião, conforme evidenciado por Alexander e Jermakowicz (2006).

Uma das consequências desse questionamento foi a determinação, na seção 108 da Lei Sarbanes-Oxley (SOX), de 2002, para que a SEC conduzisse um estudo para a adoção de um padrão de divulgação baseado em princípios. Nesse contexto também foi firmado, em setembro de 2002, o Norwalk Agreement, entre o IASB e o FASB, com o propósito de buscar eliminar as diferenças entre suas normas contábeis, tendo esses esforços de convergência, segundo Alexander e Jermakowicz (2006), recebido forte apoio da SEC, da Comissão Européia e da comunidade corporativa ao redor do mundo.

A preocupação central nas discussões sobre os US-GAAP é se a eventual inflexibilidade das normas compromete a capacidade para se acomodar a mudanças do mercado, prejudicando a qualidade e a transparência das informações financeiras. Kershaw (2005, apud BENSTON; BROMWICH; WAGENHOFER, 2006), por exemplo, afirma que normas baseadas em regras podem se tornar inúteis e disfuncionais quando o ambiente econômico muda ou quando os gestores criam transações inovadoras.

Schipper (2003) destaca que dois temas emergem dessa discussão. O primeiro é que o atual sistema de divulgação financeira nos EUAseria indesejável ou inapropriado, porque é baseado em regras, encorajando um alegado processo de compliance mental, o que, na visão de muitos, representaria um convite para a estruturação financeira e outras atividades que subvertem a preconizada qualidade da informação contábil. 0 segundo é que mudar para um sistema baseado em princípios seria desejável, porque requer o exercício apropriado do julgamento profissional.

Em síntese, os argumentos para se defender a reformulação do modelo contábil norte-americano podem ser sintetizados em duas vertentes: o padrão baseado em 
regras é de difícil aplicabilidade e oneroso, em decorrência do seu detalhamento excessivo, ao mesmo tempo em que impede a adaptação às mudanças ambientais; e o estabelecimento de critérios detalhados para o reconhecimento, a mensuração e a divulgação das operações não têm sido suficiente para evitar as ocorrências de engenharia financeira para estruturação de transações que possibilitem o alcance de objetivos contábeis, contrariando a intenção e o espírito das normas.

\section{1 - A PROPOSTA DO FASB}

Enquanto a SEC estava realizando os estudos determinados pela SOX, o FASB (2002) publicou uma proposta para consulta pública de um sistema contábil baseado em princípios, discutindo aperfeiçoamentos potenciais na qualidade e transparência da divulgação financeira nos Estados Unidos. Destacando que o objetivo central das normas deve ser o provimento de informação útil para os investidores atuais e potenciais, os credores e outros usuários, o estudo ressalta, inicialmente, que para o atendimento a esse requisito (utilidade para decisão), as qualidades primárias da informação são a relevância ${ }^{5}$ e a confiabilidade. ${ }^{6}$ A comparabilidade, ${ }^{7}$ incluindo consistência, seria, na visão do Board, uma qualidade secundária que interage com a relevância e a confiabilidade para contribuir para a utilidade da informação.

Ao justificar o estudo, o FASB (2002) destaca as preocupações surgidas sobre a qualidade e a transparência da contabilidade e da divulgação financeira americana, ressaltando que a principal é decorrente do crescente detalhamento e complexidade das normas, tendo como resultado: a dificuldade de aplicação prática; os altos custos envolvidos em sua operacionalização; a dificuldade de os profissionais se manterem atualizados; e a permissão de estruturação de operações que atendem ao teor das regras especificadas, embora contrariem a intenção e o espírito das normas, configurando o gerenciamento dos resultados.

Como diagnóstico causal para essa situação, o Board aponta que muito da complexidade e detalhes dos US-GAAP tem sido definido por demanda. No caso das exceções aos princípios, as regras contábeis criam situações em que aqueles não se aplicam às normas, geralmente em decorrência de acordos realizados para equilibrar os preceitos da utilidade da informação para o processo decisório com os problemas práticos do FASB e seus constituintes. A ocorrência de exceções, por si só, aumenta o nível de detalhe e de complexidade nas normas, porque regras e orientações específicas são necessárias para descrever e limitar as transações e eventos que são excetuadas.

Em relação às guias de implementação e interpretação, o argumento do FASB (2002) é que são criadas para garantir algum nível de comparabilidade.

5 Para ser relevante, a informação deve ser capaz de fazer uma diferença em um processo decisório, ao ajudar os usuarios a formar prédicões sobre os resultados de eventos passados, presentes e futuros ou para confirmar ou corrigir expectatîvas posteriores. A tempestividade é um aspecto implícito na relevância (IASB, 2009).

6 Para ser confiável, a informação deve ser adequadamente representada, verificável e neutra, reportando a atividade tão adequadamențe quanto possivel, não podendo ser enviesada para atender a um resultado predeterminado (IASB, 2009).

7 A comparabilidade é atendida se transações e eventos similares são contabilizados similarmente e transações e eventos diferentes são contabilizados diferentemente (IASB, 2009). 
Adicionalmente, lidam com situações em que as exceções são aplicadas, funcionando como ferramenta educacional, e, em um ambiente de crescente litígio, fornece uma resposta única a várias questões. Ressalta ainda o Board que essas orientações detalhadas proveem um efetivo mecanismo de coerção à SEC, além de atenderem à demanda de outros (incluindo contadores e auditores) para limitar a possibilidade de julgamentos profissionais posteriores.

Com esse diagnóstico, o FASB (2002) afirma a decisão de considerar a possibilidade de adotar uma referência baseada em princípios para a edição de normas, similar à usada pelo IASB, ressaltando que isso deverá exigir mudanças nas ações e no comportamento de todos os participantes do processo de elaboração e divulgação de informações financeiras, ou seja, todos os envolvidos devem estar igualmente comprometidos com essas mudanças.

Como principais referências do Proposal apresentado pelo FASB (2002), podem ser destacadas: as normas continuariam a refletir os requerimentos fundamentais de reconhecimento, mensuração e divulgação, tendo por base uma referência conceitual, mas os princípios seriam aplicados de forma mais abrangente, oferecendo poucas, talvez nenhuma, exceções aos princípios; haveria menos guias de implementação e interpretação para a aplicação das normas; poderia se incluir a TFV, desde que em situações extremamente raras. Isso, por sua vez, aumenta a necessidade de aplicação de julgamento profissional consistente com a intenção e o espírito das normas.

Por fim, o Board destaca que a implementação de um modelo baseado em princípios pode impor muitos custos ou riscos. Como exemplos, cita as possibilidades: de julgamentos profissionais, feitos de boa fé, resultarem em diferentes interpretações para eventos e transações similares, aumentando a preocupação sobre a comparabilidade; de o vazio de orientações mais específicas formuladas por órgãos com melhor referência, como o FASB, ser ocupado por outros de menor qualificação; de ocorrência de abusos, onde os princípios não sejam aplicados de boa fé, em consonância com a intenção e o espírito das normas.

Por outro lado, o FASB entende que as normas baseadas em princípios trazem os seguintes benefícios e oportunidades: devem ser mais fáceis de compreender e implementar, tendo em vista que seriam mais abrangentes; deve ajustar melhor as informações à substância econômica dos eventos e transações, a partir do uso do julgamento profissional; deve reduzir as possibilidades de engenharia financeira para o gerenciamento de resultados; deve aumentar o grau de comparabilidade, pela redução ou eliminação das exceções; permite a reação mais positiva a situações emergentes no ambiente de transformações financeiras e econômicas em que as companhias operam.

Como consequência, o FASB (2002) espera normas contábeis de alta qualidade, que aumentem a transparência da informação financeira, essencial para o funcionamento eficiente da economia, além de facilitar a convergência com as normas do IASB, o que é objetivo do Board. 


\section{2 - O ESTUDO DA SEC}

Posteriormente à proposta do FASB, a SEC (2003) divulgou relatório tratando da adoção de um sistema contábil baseado em princípios, que foi submetido à apreciação do Congresso dos EUA, conforme determinado pela SOX. O relatório conclui que nem os US-GAAP nem as IFRS são representativos de um tipo ótimo de padrões contábeis baseado em princípios. Requer que sejam estabelecidos, claramente, os objetivos de um padrão contábil. Então, para distinguir sua proposta de sistema contábil baseado em princípios das outras propostas, a SEC se refere a ele como "normas orientadas para objetivos".

De acordo com o relatório, as normas orientadas para objetivos são baseadas em uma estrutura conceitual estabelecida e consistentemente aplicada e provê estrutura e detalhes suficientes para que as normas possam ser operacionalizadas e aplicadas em uma base consistente. Devem minimizar expectativas em relação às normas e, ao mesmo tempo, evitar o uso de testes percentuais, característicos das regras detalhadas.

O relatório contrasta não apenas as normas baseadas em regras, mas também as normas baseadas em princípios, definidas como normas de alto nível, com pouca ou nenhuma orientação operacional. A rejeição de uma estrutura baseada em princípios se justifica porque, no entendimento da SEC (2003), muitas das normas requerem orientação específica para se tornarem operacionalmente viáveis. Como consequência, normas baseadas apenas em princípios requerem que contadores e auditores exercitem julgamentos contábeis para transações e eventos sem prover uma estrutura suficiente para esse julgamento. Consequentemente, o resultado de normas baseadas apenas em princípios pode ser uma significante perda de comparabilidade entre as informações divulgadas.

De qualquer forma, não obstante os profundos debates ocorridos e os estudos já realizados pela SEC e pelo FASB, permanece a indefinição política sobre a alteração do modelo contábil americano. Além do mais, a respeito da proposta da SEC, permanecem dúvidas sobre a possibilidade do preconizado equilíbrio entre princípios e regras. Benston, Bromwich e Wagenhofer (2006), por exemplo, afirmam que a história sugere que isso é um "sonho impossível", tendo em vista que quando as companhias e os auditores buscam orientação sobre uma transação que não foi considerada pelo emissor do padrão, novas regras tendem a ser estabelecidas, o que significaria a volta ao modelo que se pretende substituir.

Adicionalmente, Alexander e Jermakowicz (2006) resgatam uma manifestação da SEC, de 1942, para afirmar que a questão básica é se as demonstrações financeiras cumprem a função de esclarecimento, que é a única razão de existir. Com essa lógica, defendem que esse debate sobre normas baseadas em princípios ou em regras é uma falsa polêmica, porque as empresas e os usuários necessitam é de uma contabilidade baseada em "objetivos". 


\section{4 - CARACTERÍSTICAS QUALITATIVAS DA INFORMAÇÃO CONTÁBIL: UM PARÂMETRO DE ANÁLISE PARA A DECISÃO}

Tanto na proposta do FASB quanto no estudo da SEC, um parâmetro importante de análise para concluir sobre a pertinência ou não de se alterar o modelo contábil americano para baseado em princípios é a consideração das características qualitativas da informação financeira. O pressuposto é que os requerimentos de reconhecimento e mensuração das normas contábeis devem ser baseados nas características qualitativas da informação. O conceito considerado é a utilidade da informação para a tomada de decisão, suportada pelas características da relevância, da confiabilidade e da comparabilidade.

Para Schipper (2003), o desejo de alcançar a comparabilidade e sua contraparte temporal, a consistência, é a razão para se ter normas de divulgação contábil. Isto é, se eventos similares são contabilizados de forma equivalente, entre as empresas e ao longo do tempo, é possível se avaliar as demonstrações de diferentes entidades ou da mesma empresa em diferentes pontos do tempo, para compreender os eventos econômicos que the dão suporte. Se fosse dada pouca importância ao requisito de se aplicar o mesmo tratamento contábil a itens similares, seria razoável se esperar que os preparadores das demonstrações poderiam ser levados a escolher a divulgação que melhor atendesse às suas estratégias de comunicação.

Ainda segundo Schipper (2003), aceitando-se que a comparabilidade é desejável, a relevância e a confiabilidade auxiliam na decisão das normas a serem aplicadas para se alcançar esse objetivo, ou seja, quais os requerimentos para reconhecimento, mensuração e disclosure dos eventos econômicos. Com esse entendimento, a autora entende que, se a divulgação financeira é comparável, relevante e confiável, então seria baseada em princípios. Desse raciocínio, chama a atenção o fato de que a característica da comparabilidade é destacada como a referência básica para a normatização contábil, enquanto o FASB (2002) ressalta a relevância e a confiabilidade como qualidades primárias da informação. Para o Board, a comparabilidade, incluindo a consistência, seria uma qualidade secundária, que interage com as duas primeiras para contribuir para a utilidade da informação.

De qualquer forma, a discussão entre normas baseadas em princípios ou em regras envolve, em última instância, a possibilidade de trade-offs entre essas características qualitativas do framework conceitual. Schipper (2003) destaca, por exemplo, que muitos acreditam haver uma escolha inerente entre a relevância, representada por uma maior tempestividade na divulgação financeira, e a confiabilidade da informação. A exigência de maior relevância (tempestividade) ${ }^{8}$ requer mais estimativas e julgamentos, enquanto a confiabilidade pressupõe que a informação está suportada nos montantes transacionados, com pouca ou nenhuma estimação. Um outro exemplo também pode ser a necessidade de se escolher entre a comparabilidade, que facilita as comparações entre as empresas, e a habilidade preditiva, que facilita os cálculos do valor intrínseco. O trade-off se justifica porque essa habilidade preditiva pode requerer escolhas específicas por parte da administração, para refletir mais apropriadamente as idiossincrasias dos modelos de

8 A tempestividade é um conceito implícito na relevância (Schipper, 2003). 
negócios.

Pelas situações descritas, percebe-se que nesses trade-offs em relação às características qualitativas da informação financeira, sempre há uma dualidade entre princípios e regras. A questão é como solucionar apropriadamente esses conflitos. Seria conveniente o estabelecimento de uma hierarquia entre essas características qualitativas? Ou isso representaria um outro "engessamento" do padrão normativo?

Por fim, cabe ressaltar que, não obstante a importância de se concluir sobre o impacto de normas baseadas em princípios ou em regras nas características qualitativas da informação, faltam evidências empíricas, segundo Schipper (2003), que demonstrem o impacto das exceções e tratamentos alternativos autorizados pelas regras detalhadas para a comparabilidade, a relevância e a confiabilidade da divulgação financeira. Isso se deve, especialmente, à dificuldade de se formatar metodologicamente pesquisas que respondam objetivamente a esse tipo de questões, com evidências empíricas.

\section{5 - EFEITOS E CONSEQUÊNCIAS DOS MODELOS BASEADOS EM REGRAS OU EM PRINCÍPIOS}

Conforme destacado nas seções anteriores, os debates sobre sistema contábil baseado em regras ou em princípios têm se intensificado, particularmente nos Estados Unidos, em decorrência do processo de convergência internacional e da determinação, na Lei Sarbanes-Oxley, para que fossem empreendidos estudos para avaliar a possibilidade e a conveniência técnica e econômica de se alterar o modelo americano de normatização contábil, tendo como uma de suas consequências o Norwalk Agreement, firmado entre o IASB e o FASB em setembro de 2002, com o propósito de buscar eliminar as diferenças entre suas normas contábeis. Mais recentemente, esse movimento recebeu mais um impulso, com as discussões no âmbito do G-20 sobre os problemas decorrentes da crise financeira de 2008, sendo recomendada a adoção de esforços no sentido de consolidar o processo de convergência, conforme discutido mais apropriadamente na seção 5.3 .

O avanço das discussões não significou, necessariamente, a formação de um consenso, tanto que a proposta formulada pela SEC sugeriu um modelo intermediário entre esses dois, denominado de modelo orientado para objetivos. De qualquer forma, das discussões empreendidas é possível se identificar uma série de efeitos e consequências decorrentes da adoção de cada um desses modelos.

\section{1 - EFEITOS DE UM MODELO BASEADO EM REGRAS}

Os diversos estudos revelam que cada modelo apresenta vantagens e desvantagens, sob determinados aspectos. Em relação ao sistema contábil baseado em regras, a partir das manifestações de Nelson, Elliott e Tarpley (2002), Schipper (2003), Nelson (2003), Alexander e Jermakowicz (2006) e Benston, Bromwich e 
Wagenhofer (2006), ${ }^{9}$ são destacadas as seguintes consequências principais:

\section{a) Aumento da comparabilidade ou comparabilidade de fachada}

Um benefício alegado das regras é o aumento da comparabilidade, partindo do pressuposto de que as orientações detalhadas de como aplicar uma norma deve reduzir os efeitos de diferenças no julgamento profissional. Por outro lado, se a regra for inapropriadamente estrita, poderá estabelecer uma comparabilidade de fachada, forçando negócios não similares a um mesmo tratamento contábil, embora não haja evidências empíricas de que um maior detalhamento das regras aumente ainda mais esse risco.

\section{b) Aumento da verificabilidade}

Outro benefício da utilização de regras é o aumento da verificabilidade, isto é, o aumento do consenso sobre mensurações. Em tese, as orientações detalhadas oferecem aos contadores e aos auditores uma base de conhecimento comum, o que deve se refletir na redução da incidência de diferenças na mensuração, o que não representa sua eliminação.

\section{c) Impactos nas oportunidades de gerenciamento de resultados}

A redução da probabilidade de gerenciamento de resultados, por meio da interpretação subversiva da norma, é apontada como um efeito positivo da adoção de regras detalhadas, que eliminam ou reduzem a possibilidade de interpretação tendenciosa. Por outro lado, o detalhamento das regras tem permitido a estruturação de operações, no que tem ficado conhecido como engenharia financeira, que atendem às regras especificadas, embora contrariem a intenção das normas, conforme comprovado, particularmente, por Nelson, Elliott e Tarpley (2002).

\section{d) Reflexos no processo de regulação e nas ocorrências de litigância}

Outros efeitos decorrentes da adoção de modelo com base em regras detalhadas se referem especificamente aos interesses de contadores, auditores e reguladores: reduz as dificuldades dos profissionais com os órgãos reguladores em disputas afterthe-fact em relação a um tratamento contábil; reduz a incidência de litigância em relação a uma contabilização alegadamente defeituosa, tendo em vista que as regras detalhadas limitam os questionamentos sobre possibilidades de interpretação; reduz os custos de staff dos reguladores para compreender os julgamentos idiossincráticos dos gestores e para orientar os profissionais sobre aspectos não muito claros na norma.

\section{e) Custo de normas "precisas"}

Em relação ao dispêndio financeiro, a adoção de um sistema contábil com base em regras "precisas" tem como consequência o aumento dos custos com experts, para interpretar as regras ou para estruturar contratos/acordos para evadir normas legais.

9 São estudos teóricos ou experimentais, reforçando a carência de evidências empíricas destacadas no capítulo 4. 


\section{2 - CONSEQUÊNCIAS DE UM MODELO BASEADO EM PRINCÍPIOS}

Por outro lado, a implementação de um sistema contábil baseado em princípios também traz algumas consequências positivas e outras negativas, entre as quais, a partir das reflexões de Nelson, Elliott e Tarpley (2002), Schipper (2003), Nelson (2003), Alexander e Jermakowicz (2006) e Benston, Bromwich e Wagenhofer (2006), podem ser destacadas:

\section{a) Efeitos sobre a comparabilidade}

Em decorrência da adoção de um sistema contábil baseado em princípios pode-se ter dois tipos de efeitos distintos sobre a comparabilidade das informações: um negativo, como consequência das diferenças de interpretações decorrentes dos julgamentos profissionais requeridos; e outro positivo, tendo em vista que a eliminação das exceções de escopo e de tratamento torna as informações mais comparáveis.

\section{b) Volatilidade do lucro divulgado}

A eliminação das regras de exceções de escopo e de tratamento direcionadas para reduzir a volatilidade do resultado tem como consequência óbvia o aumento da variabilidade dos lucros divulgados. Apesar dessa suavização das flutuações inerentes atender aos interesses de diversos agentes econômicos, o próprio FASB (2002) argumenta que essas exceções de escopo e tratamentos alternativos permitidos nos US-GAAP obscurecem a substância econômica dos eventos e transações. Em suma, essa maior volatilidade traduz mais adequadamente a essência econômica na divulgação financeira, embora possa influenciar efeitos econômicos indesejados, principalmente em decorrência da prociclicalidade. ${ }^{10}$

\section{c) Inconsistências no processo de transição}

A adoção de um sistema baseado em princípios requer um processo demorado de substituição de todo o arcabouço normativo e até da literatura contábil. Nesse sentido, o processo de migração deve acontecer paulatinamente, o que compromete a característica qualitativa da consistência, oferecendo informações não comparáveis ao longo do tempo. Em suma, a qualidade da divulgação financeira é temporariamente diminuída, em dimensão desconhecida, durante o período de transição. Uma alternativa a esse problema seria a aplicação retroativa, que implica em restabelecer a divulgação financeira para todos os períodos apresentados, o que garantiria a consistência e a comparabilidade, mas isso impõe maiores custos às empresas, aos contadores e aos auditores.

\section{d) Expertise de contadores e auditores}

Como decorrência do fato de que as normas baseadas em princípios exigem aumento substancial no julgamento profissional, é de se esperar que a expertise requerida, tanto de contadores quanto de auditores deva ser substancialmente

\footnotetext{
10 Se caracteriza pela tendência à super avaliação do valor justo dos ativos nos momentos de expansão econômica, enquanto nos momentos de retração, a redução do valor dos ativos tende a ser mais acentuada do que seria indicada pela substância econômica, confiğurando um movimento de maior volatilidade nos resultados apurados.
} 
mais relevante. Se as orientações detalhadas são removidas, aumenta o número de estimativas e julgamentos requeridos, com 0 consequente impacto nas responsabilidades dos profissionais, particularmente em relação ao processo de mensuração. Se a ênfase na expertise de mensuração aumenta, uma potencial implicação para a educação contábil é a necessidade de incluir ferramentas de mensuração no processo de formação dos contadores.

\section{e) Oportunidades para outros órgãos reguladores}

A ausência de regras esclarecedoras, por parte do regulador central, pode fazer com que outros órgãos, de menor representatividade, passem a suprir os profissionais com orientações específicas para a aplicação das normas baseadas em princípios. 0 problema é que os órgãos que podem ocupar esse espaço não necessariamente têm o mesmo nível de qualificação do regulador central, comprometendo a efetividade prática do modelo instituído com base em princípios.

\section{f) Ajustamento à substância econômica dos eventos e transações}

Ao menos em tese, as normas contábeis baseadas em princípios devem ser mais fáceis de se compreender e implementar, além de facilitar o ajustamento à substância econômica dos eventos e transações. Por outro lado, a subjetividade implícita nos julgamentos profissionais pode facilitar a ocorrência de abusos, em que os princípios incorporados nas normas não sejam aplicados de boa fé.

\section{g) Resistência dos auditores}

Como forma de se prevenir de eventuais riscos de litigância after-the-fact, os auditores tendem a resistir à adoção de normas com maior grau de subjetividade, sob o argumento de que esse tipo de norma aumenta a pressão por demandas oportunistas, otimismo exagerado ou administradores desonestos. Por outro lado, se questionados posteriormente por terem aceitado exceções exigidas pela administração em determinada situação, podem simplesmente alegar julgamento profissional.

\section{h) Custo de normas "imprecisas"}

A instituição de um modelo baseado em princípios, com normas “imprecisas”, tem como consequência uma maior exposição a custos de erro e de risco de litigância. A reação é uma preocupação maior com o compliance em relação ao espírito das normas.

\section{3 - AS TENDÊNCIAS DO DEBATE PRINCÍPIOS VERSUS REGRAS}

Segundo Giner e Ress (2005), alguns especialistas acham que, ao contrário das críticas recentes, as normas baseadas em regras podem se tornar dominante nos EUA e na Europa, considerando que o risco de litigância contra os preparadores das demonstrações e os auditores tendem a forçar o surgimento de normas de implementação que reduzam a exposição nos julgamentos profissionais. Na ausência de um posicionamento mais claro do órgão emissor das normas, os autores 
entendem que deve ocorrer a busca por pronunciamentos de outros órgãos e até de jurisprudências, que os auxiliem. Daí o pressuposto de que um modelo baseado em regras, no fundo, deve prevalecer.

Não obstante esse entendimento, o fato é que o contexto das discussões aponta para uma tendência de se priorizar o modelo baseado em princípios, com o argumento principal de que ele aumenta a transparência e a qualidade da informação financeira, além de facilitar a convergência com as normas do IASB, que, como destacado, é visto como baseado em princípios, apesar das ressalvas destacadas na seção 2.2.

Essa tendência é reforçada, por exemplo, pelo diagnóstico realizado pelo grupo dos países mais ricos do mundo, G-20 (2009), sobre a crise financeira que eclodiu em 2008, quando foi recomendado, textualmente, que os órgãos responsáveis pela emissão de normas contábeis deveriam reduzir a sua complexidade e aumentar os esforços para facilitar a convergência global para uma estrutura simples de normas de alta qualidade.

Como reflexão, Schipper (2003) salienta que a adoção de modelo baseado em princípios requer que reguladores, investidores, credores e outros usuários devem aceitar as consequências dessa aplicação, incluindo mais divergências na prática, dada a subjetividade implícita nos julgamentos profissionais.

Outro fato a se destacar é que as discussões sobre benefícios, custos, oportunidades e riscos dos dois modelos em questão são essencialmente teóricas, e às vezes opinativas, salvo as questões relacionadas ao gerenciamento de resultados. Isso porque é excepcionalmente difícil se formatar metodologicamente uma pesquisa que permita responder objetivamente questões dessa natureza, tendo em vista que requereria, em tese, o acompanhamento cotidiano dos preparadores das demonstrações e dos auditores no tratamento dos eventos e/ou transações a serem reconhecidos, mensurados e divulgados, para identificar como eles reagem a normas que permitem maior ou menor espaço para o julgamento profissional.

Considerando que é uma questão de natureza comportamental, uma alternativa metodológica a esse tipo de dificuldade pode ser a utilização da pesquisa experimental. ${ }^{11}$ Bazerman (2004) ressalta a importância desse tipo de método de pesquisa, notadamente para as situações em que as pessoas (o autor cita o exemplo dos auditores) são demandadas para julgamentos imparciais, mas sofrem, inconsciente e poderosamente, vieses que correspondem ao interesse próprio do juiz, configurando o fenômeno definido pelos psicólogos como "viés do interesse próprio".

Cuccia, Hackenbrack e Nelson (1995), ${ }^{12}$ por exemplo, avaliaram, por meio de experimentos, se os incentivos que os contadores recebiam para divulgar informações agressivas ou conservadoras mudavam a forma como os profissionais interpretavam as normas. Os resultados demonstraram que: quando a norma é imprecisa (vaga), os 11 Método de investigação que envolve a manipulação de tratamentos na tentativa de estabelecer relações de causa-efeito nas variáveis investigadas (THOMAS; NELSON, 2002).

12 Embora essa pesquisa tenha sido realizada em um momento anterior à efervescência das discussões tratadas no presente estudo, aplica-se ao caso em questão, tendo em vista que avalia a reação dos contadores/auditores em relação a normas mais vagas (com maior espaço para o julgamento profissional) ou mais restritas (regras). 
profissionais a interpretam de forma a atender os seus propósitos de divulgação; e quando a norma é mais rígida, os contadores utilizam o viés na avaliação das evidências de suporte, alcançando, por outros meios, a posição preferida. Essa pesquisa dá a dimensão do quão difícil é se definir um modelo ótimo entre o estabelecimento de normas vagas, baseadas em princípios, ou restritas, com base em regras.

\section{6 - A SITUAÇÃO BRASILEIRA}

Considerando a natureza de um sistema contábil baseado em princípios, em que são estabelecidos preceitos gerais que servem de referência para o julgamento profissional quanto à melhor forma de evidenciar a essência econômica das operações, fica claro que esse modelo é mais apropriado onde há uma tradição jurídica consuetudinária (common law). ${ }^{13}$

Esse não é o caso brasileiro, no qual prevalece a tradição code law, sendo - contador acostumado a cumprir normas, conforme destacam Lopes, Galdi e Lima (2009). Essa característica é reforçada, inclusive, no padrão de formação dos profissionais vigente nas universidades. Um dos exemplos históricos desse padrão de comportamento é o fato de que as normas contábeis adotadas no Brasil, em particular para as sociedades anônimas, foram, ao longo dos tempos, fortemente influenciadas pelas determinações legais. A legislação fiscal também tem papel determinante na adoção de certas práticas contábeis, como, por exemplo, no caso das operações de arrendamento mercantil de natureza financeira, em que claramente são desconsiderados preceitos básicos da teoria contábil para se atender a requisitos tributários.

Não obstante esse contexto, várias ações têm sido adotadas no Brasil, com vistas ao processo de convergência internacional, com a adoção dos padrões contábeis do IASB, que diferem substancialmente da prática contábil que historicamente vinha sendo adotada no país. Ainda durante a década de 1990, segundo a CVM (2007), começaram os esforços institucionais nesse sentido, mediante o aperfeiçoamento das normas contábeis, com a incorporação de preceitos dos padrões do IASB, e a apresentação de anteprojeto de lei para a alteração da legislação societária, posteriormente transformada no Projeto de Lei (PL) 3.741/2000. Em 2001, o BCB editou a Circular 3.068/2001, tratando dos procedimentos de reconhecimento e mensuração de ativos financeiros, iniciando o processo de adaptação das normas do Plano Contábil das Instituições do Sistema Financeiro Nacional (Cosif) aos parâmetros das normas internacionais. Outro evento importante nesse processo foi a criação do Comitê de Pronunciamentos Contábeis (CPC), por meio da Resolução do Conselho Federal de Contabilidade (CFC) $\mathrm{n}^{\circ}$ 1.055, de 7.10.2005, com a missão de estudar, preparar e emitir pronunciamentos técnicos com vistas ao processo de convergência aos padrões internacionais.

No ano de 2007, dois fatos marcantes impulsionaram o movimento de

13 Não obstante a aparente contradição em relação ao fato de que os US-GAAP são geralmente citados como exemplo de modelo baseado em regras, embora a tradição jurídica dos Estados Unidos seja consuetudinária. 
convergência das normas brasileiras ao padrão internacional. Primeiro, a edição da Instrução CVM n 457/2007, determinando que, a partir do exercício findo em 2010, as companhias abertas devem apresentar demonstrações financeiras consolidadas adotando o padrão contábil internacional - normas do IASB. Segundo, a promulgação da Lei $n^{\circ}$ 11.638, de 28.12.2007, alterando dispositivos da legislação societária relativos ao processo de elaboração e de divulgação das demonstrações financeiras.

Embora essa alteração na legislação tenha sido fruto de longo debate, as pesquisas acadêmicas produzidas no Brasil sobre o tema geralmente têm se concentrado nos benefícios para a inserção internacional dos mercados financeiros e de capitais locais e das empresas brasileiras, em particular com a redução dos custos de elaboração das demonstrações financeiras e o aumento da transparência, como pode ser constatado nos estudos de Leite (2002), Lemes e Carvalho (2004), Santos, Sarlo Neto e Teixeira (2004) e Kroenze e Cunha (2008), por exemplo. Não há evidências, porém, de estudos que avaliem os aspectos mais filosóficos dos modelos de normatização, destacando os benefícios, os custos, as oportunidades e os riscos da alteração do modelo de normatização para baseado em princípios.

Como se percebe, a adoção no Brasil de um modelo contábil tido como baseado em princípios (não obstante as ressalvas já destacadas anteriormente nesse estudo), com mais espaço para o julgamento profissional, embora tenha sido precedida de estudos e discussões no âmbito das organizações profissionais e dos órgãos reguladores do mercado, não foi acompanhada de um debate acadêmico com a amplitude e a abrangência requerida. Questões como o impacto cultural decorrente da alteração do modelo, a eventual defasagem de expertise profissional e o grau de preparo das universidades brasileiras para atender aos novos requisitos de formação dos contadores, por exemplo, parecem não ter sido suficientemente discutidas.

Ademais, se é verdade que as discussões empreendidas desde a década de 1990 alcançaram os agentes envolvidos com o mercado de capitais, o sistema financeiro e as grandes corporações, incluídas as firmas de auditoria, a aprovação do CPC PME, que disciplina o processo contábil das pequenas e médias empresas, alcança um público bem mais amplo. o impacto mais imediato é uma necessidade de discussão sobre a adoção de ações que supram uma parcela relevante da profissão, envolvida no atendimento a esse tipo de empresas, com o conhecimento sobre o novo modelo contábil, que exige muito mais julgamento profissional que o anterior.

Outra questão a se destacar no processo de convergência do padrão brasileiro às normas do IASB, é que os pronunciamentos do CPC não incorporam um elemento importante das divulgações das IFRS, que são os Basis for Conclusions, onde o Board justifica as razões que levaram a se optar por emitir o pronunciamento de uma forma e não de outra. Isso é particularmente importante para orientar o profissional em seu julgamento profissional, permitindo uma reflexão sobre os objetivos da norma. Como o CPC não está traduzindo o Basis for Conclusions, é possível que isso aumente ainda mais o risco de divergências relevantes na interpretação das normas, considerando a ausência desse suporte para os profissionais.

Por fim, também é importante ressaltar o fato de que as características do ambiente econômico e legal no Brasil contemplam outros tipos de dificuldades para 
a implementação de um modelo contábil baseado em princípios. Isso porque os pronunciamentos do CPC, para terem força coercitiva, precisam ser homologados/ referendados por órgãos reguladores abrangentes como o Conselho Federal de Contabilidade (CFC) e a Comissão de Valores Mobiliários (CVM), além de diversos outros de natureza setorial, com poderes de regular segmentos econômicos específicos, tais como: o Conselho Monetário Nacional (CMN) ou Banco Central do Brasil (BCB); a Superintendência de Seguros Privados (SUSEP); a Agência Nacional de Energia Elétrica (ANEEL); a Secretaria de Previdência Complementar (SPC); Agência Nacional de Transportes Terrestres (ANTT); Agência Nacional de Saúde (ANS); entre outros. Essa estrutura complexa pode, eventualmente, fazer com que determinado pronunciamento seja referendado por alguns órgãos, mas não por outros, como evidenciado na tabela a seguir:

Tabela 1: Quantidade de pronunciamentos aprovados pelo CPC e pelos órgãos reguladores ${ }^{14}$

\begin{tabular}{ccc}
\hline Descrição & Quant. & Perc. \\
\hline Pronunciamentos em vigor & 40 & \\
Aprovados pela CVM & 40 & $100.00 \%$ \\
Aprovados pelo CFC & 40 & $100.00 \%$ \\
Aprovados pela ANS & 38 & $95.00 \%$ \\
Aprovados pela ANEEL & 28 & $70.00 \%$ \\
Aprovados pela SUSEP & 13 & $32.50 \%$ \\
Aprovados pela ANTT & 12 & $30.00 \%$ \\
Aprovados pelo CMN & 4 & $10.00 \%$ \\
\hline
\end{tabular}

Fonte: Sítio do CPC

Como se percebe, apenas a CVM e o CFC aprovaram todos os pronunciamentos instituídos pelo CPC. Entre os reguladores setoriais, a ANS aprovou 95\% deles (só não aprovou o CPC 11, relativo a contratos de seguros, e o CPC 41, que trata de resultado por ação), enquanto o CMN só adotou 10\% desses pronunciamentos.

Outra situação que também podeocorrer é determinado regulador adaptar alguns pronunciamentos do CPC, incorporando outros parâmetros/requerimentos em suas normas. É o caso, por exemplo, das normas previstas no Cosif para o reconhecimento, mensuração, apresentação e evidenciação dos instrumentos financeiros, que contemplam aspectos bem mais específicos que os dos Pronunciamentos 38, 39 e 40 do CPC.

Por fim, chama a atenção o fato de que a estrutura conceitual é um requisito essencial para a adoção de um modelo contábil baseado em princípios, mas o Pronunciamento Conceitual Básico do CPC só foi aprovado pela CVM, pelo CFC, pela SUSEP, pela ANEEL e pela ANTT, mas ainda não foi referendada pelo CMN nem pela ANS.

14 Desconsiderando-se o Pronunciamento Conceitual Básico - Estrutura Conceitual e o CPC PME, relativo às pequenas e médias empresas. 


\section{7 - CONSIDERAÇÕES FINAIS}

Tendo em vista os propósitos do presente estudo, a revisão da literatura indica que, não obstante haver certo consenso de que um sistema contábil baseado em princípios apresenta uma série de benefícios, que se traduzem em oportunidades profissionais, em relação a uma estrutura normativa baseada em regras, a adoção de um modelo que exige mais julgamento profissional e uso de critérios subjetivos também traz custos e riscos.

Se é esperado, por exemplo, que a qualidade da informação melhore, tendo em vista a possibilidade de o contador e o auditor poderem escolher critérios de reconhecimento, mensuração e divulgação que melhor reflitam a essência econômica das transações, por outro lado há o risco de que essa prerrogativa profissional não seja aplicada de boa fé ou mesmo que aumente o risco de litigância, com o questionamento, after-the-fact, dos critérios utilizados no julgamento profissional. Esse é apenas um exemplo de uma série de questões mapeadas ao longo do estudo, que reproduz uma dualidade entre aspectos positivos e negativos de cada um dos modelos.

A relação de benefícios e custos, oportunidades e riscos, vantagens e desvantagens, aspectos positivos e negativos da adoção de sistemas contábeis baseados em princípios ou em regras aumenta a importância dos argumentos expostos no estudo da SEC, de que a melhor solução não necessariamente está em se optar por um modelo ou outro. A solução pode ser um sistema intermediário, que atenda objetivamente à função intrínseca da Contabilidade, o esclarecimento da situação econômico-financeira da empresa, aumentando a condição preditiva por parte do usuário.

A reflexão sobre os trade-offs das características qualitativas da informação financeira parece ser um elemento relevante de análise para se concluir sobre o modelo que melhor atende às necessidades dos diversos usuários, não obstante as dificuldades de se formatar metodologicamente pesquisas que ofereçam respostas claras a esse tipo de questão.

\section{REFERÊNCIAS}

ALEXANDER, David; JERMAKOWICZ, Eva. A True and Fair View of The Principles Rules Debate. Abacus, v. 42, 2, p. 132-164, 2006.

BALL, Ray; BROWN, Philip. An empirical evaluation of accounting income numbers. Journal of Accounting Research, v. 6, 6, 1968, p. 159-178.

BAZERMAN, Max H. Processo decisório. 5.ed. São Paulo: Campus, 2004.

BEAVER, W. H. The information content of earnings announcements empirical research in accounting: selected studies 1968. Journal of Accounting Research, Suplement, 
v. $6,6,1968$. p. 67-92.

BANCO CENTRAL DO BRASIL. Plano Contábil das Instituições do SFN (COSIF). Disponível em <http://www.bcb.gov.br/?COSIF>. Acesso em 6 nov, 2009.

BENSTON, George J.; BROMWICH, Michael; WAGENHOFER, Alfred. Principles- Versus Rules-Based Accounting Santandards: The FASB's Santandard Setting Strategy. Abacus, v. 42, 2, 2006.

COMISSÃO DE VALORES MOBILIÁRIOS (CVM). Instrução n 457, de 13.7.2007. Dispõe sobre a elaboração e divulgação das demonstrações financeiras consolidadas, com base no padrão contábil internacional emitido pelo International Accounting Standards Board - IASB. Disponível em <www.cvm.gov.br>. Acesso em 29 Ago, 2010.

COMITÉ DE PRONUNCIAMENTOS CONTÁBEIS (CPC). Pronunciamentos 38, 39 e 40. Disponível em <http://www.cpc.org.br/pronunciamentosIndex.php>. Acesso em 7 mai, 2010.

CONSELHO FEDERAL DE CONTABILIDADE (CFC). Resolução 1.055, de 7.10.2005. Cria o Comitê de Pronunciamentos Contábeis (CPC), e dá outras providências. Disponível em <http://www.cpc.org.br/pdf/RES 1055.pdf>. Acesso em 29 Ago, 2010.

CUCCIA, Andrew D.; HACKENBRACK, Karl; NELSON, Mark W. The Ability of Professional Standards to Mitigate Aggressive Reporting. The Accounting Review, v. 70, Apr 1995, p. 227-248.

FINANCIAL ACCOUNTING STANDARD BOARD (FASB). Proposal for a Principles-Based Approach to U.S. Standard Setting. October, 2002. Disponível em <http://www. fasb.org.br>. Acesso em 12 ago, 2009.

G-20WORKING GROUP. Enhancing Sound Regulation and Strengthening Transparency: Final Report. March, 2009. Disponível em <http: //www.g20.org>. Acesso em 20 ago. 2009.

GALLO, José A. A. Contratos Incompletos. Nova Lima, MG: 2009. 69f Dissertação (Mestrado em Direito Empresarial) - Faculdade de Direito Milton Campos, Nova Lima, 2009.

GINER, B.; REES, W. The Adoption of IAS in Europe: Introduction. European Accounting Review, v. 14, 1, 2005.

HENDRIKSEN, Eldon S.; VAN BREDA, Michael F. Teoria da Contabilidade. São Paulo: Atlas, 1999.

INTERNATIONALACCOUNTING STANDARDS BOARD (IASB). IFRS - Normas Internacionais de Relatório Financeiro. São Paulo: Ibracon, 2009.

IUDÍCIBUS, Sérgio de; LOPES, Alexsandro Broedel (coord.). Teoria Avançada da Contabilidade. São Paulo: Atlas, 2004.

JREIGE, Elionor Farah. True and Fair View: um entrave ou um impulso para a 
Contabilidade? Caderno de Estudos FIPECAFI, v. 10, 17, jan/abr, 1998, p.35-46.

KOTHARI, S. P. Capital markets research in accounting. Journal of Accounting and Economics, v. 31, 2001. p. 105-231.

KROENKE, Adriana; CUNHA, Jacqueline V. A. Harmonização contábil: um estudo bibliométrico no Congresso USP e EnANPAD de 2004 a 2007. In SEMEAD, 11, 2008. Anais eletrônicos... Disponível em <http:/ / www.ead.fea.usp.br/semead/11semead/ resultado/trabalhosPDF/ 743.pdf>. Acesso em 6 set, 2010.

LEITE, Joubert S. J. Normas contábeis internacionais: uma visão para o futuro. Cadernos da FACECA, Campinas, v. 11, 1, jan-jun-2002. p. 51-65.

LEMES, Sirlei; CARVALHO, Luis N. G. Efeito da convergência das normas contábeis brasileiras para as normas internacionais do IASB. Congresso USP de Controladoria e Contabilidade, 4, 2004, São Paulo, Anais.... Disponível em < http: / / www. congressousp. fipecafi.org/ artigos42004/345.pdf>. Acesso em 6 set., 2010.

LOPES, Alexsandro Broedel. A Informação Contábil e o Mercado de Capitais. São Paulo: Pioneira Thomson Learning, 2002.

; IUDICIBUS, Sérgio de; MARTINS, Eliseu. Sobre a Necessidade de se Estudar Contabilidade e (e não ou) Finanças. Editorial. Revista Contabilidade \& Finanças, 47, mai/ago. 2008, p. 5.

; GALDI, Fernando Caio; LIMA, Iran Siqueira. Manual de Contabilidade e Tributação de Instrumentos Financeiros e Derivativos. São Paulo: Atlas, 2009.

NELSON, Mark W.; ELLIOTT, John; TARPLEY, Robin L. Evidence from Auditors about Manager's and Auditor's Earnings Management Decisions. The Accounting Review, v.77, Suplement, 2002, p.175-202.

. Behavioral Evidence on the Effects of Principles- and Rules-Based

Standards. Accounting Horizons, v. 17, 1, 2003, p.91-104.

NIYAMA, Jorge Katsumi; SILVA, César Augusto Tibúrcio. Teoria da Contabilidade. São Paulo: Atlas, 2008.

PARKER, R. H.; NOBES, O. W. True and Fair: a survey of UK financial directors. Journal of Business Finance \& Accounting, April 1991, p. 359-375.

SANTOS, Luis S. R.; SARLO NETO, Alfredo; TEIXEIRA, Aridelmo J. C. Projeto de Lei 3.741/2000 - Efeitos Sobre A Avaliação dos Ativos de Uma Empresa do Setor Explorador de Granito: Um Estudo de Caso. Congresso USP de Controladoria e Contabilidade, 4, 2004, São Paulo, Anais... Disponível em <http: / /www.congressousp. fipecafi.org/ artigos42004/406.pdf>. Acesso em 6 set., 2010.

SECURITIES AND EXCHANGE COMMISSION (SEC). Study Pursuant to Section 108(d) of the Sarbanes-Oxley Act of 2002 on the Adoption by the United States Financial Reporting System of a Principles-Based Accounting System. 2003. Disponível em <www.sec.gov/news/studies/principlesbasedstand.htm>. Acesso em 8 dez, 2009. 
SCHIPPER, Katherine. Principles-Based Accounting Standards. Accounting Horizons, v. 17, 1, 2003, p.61-72.

. The Introduction of International Accounting Standards in Europe: Implications for International Convergence. European Accounting Review, v. 14, 1, 2005.

THOMAS, J. \& NELSON, J. Métodos de pesquisa em atividade física e saúde. 3.ed. São Paulo: Artmed Editora, 2002.

UNITED STATES OF AMERICA (USA). Sarbanes-Oxley Act of 2002. Disponível em <http: //www.sarbanes-oxley.com/section.php>. Acesso em 24 set, 2009. 


\section{ENDEREÇO DOS AUTORES:}

\section{José Alves Dantas}

Professor do Centro Universitário Euro-Americano.

Sces - Trecho 0 - Conj. 05 - L4 Sul - Avenida das Nações Sul

Brasília, DF - Brasil

70200-001

\section{Fernanda Fernandes Rodrigues}

Universidade de Brasília

Departamento de Ciências Contábeis e Atuariais.

Campus Universitário Darcy Ribeiro - Asa Norte

Prédio da Face - CCA - Brasília, DF - Brasil

70910-900

\section{Jorge Katsumi Niyama}

Universidade de Brasília

Faculdade de Estudos Sociais Aplicados, Departamento de Ciências Contábeis e Atuariais.

Campus Universitário Darcy Ribeiro - Asa Norte Prédio da FACE - $2^{\circ}$ Andar - Salas B1-02 - Brasília, DF - Brasil 70910-900

\section{Paulo Cesar de Melo Mendes}

Universidade de Brasília

Departamento de Ciências Contábeis e Atuariais.

Campus Universitário Darcy Ribeiro - Asa Norte

Prédio da FACE, $2^{\circ}$ andar, salas B1-02 - Brasília, DF - Brasil

70910-900 